\title{
Strength Mismatch Effects on Charpy Absorbed Energy and CTOD Fracture Toughness*
}

\author{
by Yusuke Ito**, Yasuhito Takashima*** and Fumiyoshi Minami***
}

\begin{abstract}
In order to examine the difference between the sensitivity of Charpy absorbed energy, ${ }_{\mathrm{v}} E$, and critical CTOD, $\delta_{\mathrm{cr}}$, to strength mismatch in welds, the numerical analysis was conducted. This study adopted the evaluation method based on the Weibull stress criterion for calculation of $\mathrm{v}_{\mathrm{v}} E$ and $\delta_{\mathrm{cr}}$ assuming that the critical Weibull stress at brittle fracture is independent of the strength mismatch as well as the loading rate.

This analysis showed that the ${ }_{\mathrm{V}} E$ and $\delta_{\mathrm{cr}}$ decreased as the location of the $\mathrm{V}$-notch or crack approached welded interface. The change in ${ }_{\mathrm{v}} E$ was larger than that in $\delta_{\mathrm{cr}}$, because the strength mismatch caused acceleration of strain rate and decrease in temperature rise near the V-notch as well as plastic constraint. This result indicates that the sensitivity of the ${ }_{\mathrm{v}} E$ and $\delta_{\mathrm{cr}}$ to strength mismatch is different depending on the loading rate.
\end{abstract}

Key Words: Notch toughness, Fracture toughness, Weibull stress, Brittle fracture, Strength mismatch, Impact loading

\section{Introduction}

Fracture toughness values are often estimated from the Charpy absorbed energy, $\mathrm{v} E$ by using empirical correlation. The correlation taking account of a temperature shift due to difference in loading rate between Charpy impact test and fracture toughness test was obtained for steels ${ }^{1)}$. If the correlation is applicable to welds, it is useful for estimating fracture toughness of welds.

It is concerned that the strength mismatch affects the correlations between the ${ }_{\mathrm{v}} E$ and critical CTOD, $\delta_{\mathrm{cr}}$. It is reported that the strength mismatch affects ${ }_{\mathrm{V}} E^{2,3)}$ and the $\delta_{\mathrm{cr}}{ }^{4)}$ respectively. When there is the hardened part around the V-notch or crack, the ${ }_{\mathrm{v}} E$ and $\delta_{\mathrm{cr}}$ decrease. This is caused by plastic constraint. The Charpy specimen is subjected to dynamic loading, whereas the fracture toughness specimen is subjected to static loading. The flow stress is elevated and the toughness is deteriorated by acceleration of strain rate ${ }^{1)}$. The strain rate for Charpy specimen is affected by the strength mismatch ${ }^{3)}$. Thus, in addition to the plastic constraint, the effect of the loading rate should be taken in consideration.

In this paper, numerical analysis based on Weibull stress approach on brittle fracture was conducted in order to investigate the influence of strength mismatch on ${ }_{\mathrm{V}} E$ and $\delta_{\mathrm{cr}}$. The stress fields were analyzed for Charpy specimen and CTOD specimen of welded joint of dissimilar steels.

\footnotetext{
*Received: 2016.10 .17

${ }^{* *}$ Student Member, Graduate, school of Engineering Osaka University

${ }^{* * *}$ Member, Joining and Welding Research Institute Osaka University
}

\section{FE analysis procedure}

The stress fields in the Charpy specimen and the 3PB specimen were analyzed with ABAQUS Standard ver-6.12. The configurations of the V-notched Charpy specimen and the three-point-bend (3PB) specimen employed in the FE analysis are shown in Fig. 1. The target of this analysis was the welded joint of dissimilar steels, which had notch or crack in softer material. The CTOD fracture toughness specimen of base metal (CTOD-B-specimen) and the Charpy specimen of base metal (CVN-B-specimen) are shown in Fig. 1(a) and Fig. 1(c),

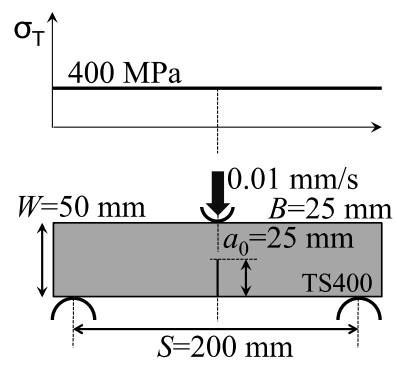

(a) Homogeneous $3 \mathrm{~PB}$ specimen of TS400 (CTOD-B-specimen)

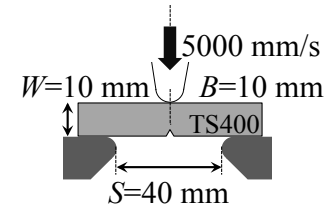

(c) Homogeneous Charpy specimen of TS400 (CVN-B-specimen)

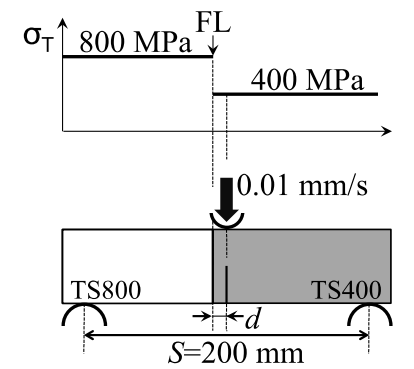

(b) 3PB specimen including the pre-crack within the TS400 (CTOD-J-specimen)
Fig. 1 Schematic illustration of the target in this study 
respectively. The CTOD fracture toughness specimen of welded joints (CTOD-J-specimen) is shown in Fig. 1(b), and V-notch Charpy specimen of welded joints (CVN-J-specimen) is shown in Fig. 1(d). The Charpy specimen has the standard $2 \mathrm{~mm}$ V-notch parallel to the welded interface (or fusion line, FL). The 3PB specimen has the sharp crack parallel to FL, whose length $a$ is $W / 2$, where the $W$ means the width of specimen. The distance from FL to V-notch or crack, $d$ was varied from $1 \mathrm{~mm}$ to $5 \mathrm{~mm}$. The FE models used is shown in Fig. 2. Because of symmetry of the specimen, one quarter of the CVN-B- and the CTOD-B-specimen, and one half of the CVN-J- and the CTOD-J-specimen were modeled. The FE analysis used the eight-node element with eight Gaussian integration points, and the minimum element size near the notch root and crack tip had dimensions of $0.05 \times 0.05 \times 0.2 \mathrm{~mm}$.

In the FE analysis, the power-hardening law of Swift type was adopted:

$$
\bar{\sigma}=\sigma_{Y}\left(1+\bar{\varepsilon}_{p} / \alpha\right)^{n}
$$

where $\bar{\sigma}$ and $\bar{\varepsilon}_{p}$ are the equivalent stress and equivalent plastic strain, respectively, $\sigma_{\mathrm{Y}}$ is the yield stress, and $n$ and $\alpha$ are material constants ( $n$ being a strain-hardening coefficient). The Young's modulus, $E$, and Poisson's ratio, $v$, are 206,000 MPa and 0.3 , respectively. The mechanical properties of

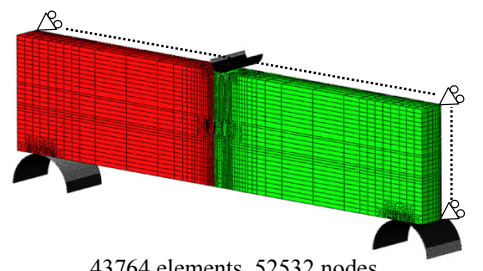

43764 elements, 52532 nodes

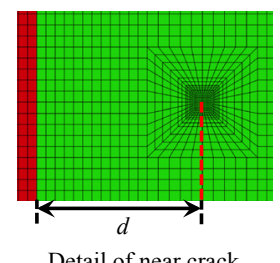

Detail of near crack

(a) Pre-cracked 3PB specimen

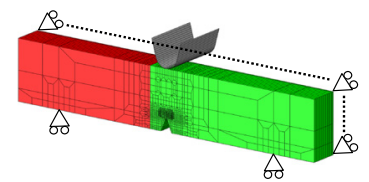

8151 elements, 9456 nodes

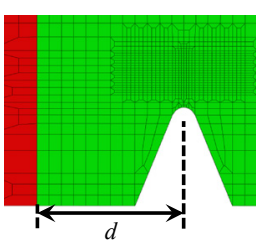

Detail of near V-notch (b) V-notched Charpy specimen
Fig. 2 FE models used in this study

Table 1 Mechanical properties used in FE analysis

\begin{tabular}{|c|c|c|c|c|}
\hline Material & $\sigma_{\mathrm{Y}}(\mathrm{MPa})$ & $\sigma_{\mathrm{T}}(\mathrm{MPa})$ & $\sigma_{\mathrm{Y}} / \sigma_{\mathrm{T}}$ & $\varepsilon_{\mathrm{T}}(\%)$ \\
\hline TS400 & 300 & 400 & 0.75 & 26 \\
\hline TS800 & 720 & 800 & 0.90 & 10 \\
\hline
\end{tabular}

$\sigma_{\mathrm{Y}}:$ Yield stress, $\sigma_{\mathrm{T}}$ : Tensile strength, $\varepsilon_{\mathrm{T}}$ : Uniform elongation

Table 2 Thermal constants used in FE analysis

\begin{tabular}{|c|c|c|c|}
\hline$C(\mathrm{~J} / \mathrm{kg} \cdot \mathrm{K})$ & $\rho\left(\mathrm{kg} / \mathrm{mm}^{3}\right)$ & $\lambda(\mathrm{W} / \mathrm{K} \cdot \mathrm{m})$ & $\alpha_{\mathrm{L}}(1 / \mathrm{K})$ \\
\hline $4.69 \times 10^{2}$ & $7.86 \times 10^{-6}$ & 51.8 & $1.2 \times 10^{-5}$ \\
\hline
\end{tabular}

$C$ : Specific heat, $\rho$ : Density, $\lambda$ : Thermal conductivity, $\alpha_{\mathrm{I}}:$ Coefficient of liner expansion elastic-plastic materials at the room temperature and static loading rate used in this study are shown in Table 1 .

In the FE analysis of the Charpy impact test, the strain rate effect on flow stress and the temperature rise during impact loading were considered. These effects were evaluated with the strain rate-temperature parameter, $R$ proposed by Bennett et $\mathrm{al}^{5 \text { ) }}$. On the other hand, the uniform elongation was assumed to be independent of the strain rate and temperature. This analysis assumed transferring $90 \%$ of plastic work to heat ${ }^{6)}$. The thermal constants used in this analysis are shown in Table 2. The inertial effect during impact loading was eliminated by quasi-static analysis in this study.

The loading rate for the Charpy specimen was $5000 \mathrm{~mm} / \mathrm{s}$ and that for the $3 \mathrm{~PB}$ specimen was $0.01 \mathrm{~mm} / \mathrm{s}$ in accordance with testing standard. The value of ${ }_{\mathrm{V}} E$ was evaluated as an amount of work done by striker and that of $\delta$ was calculated with the load and CMOD, respectively.

\section{Strength mismatch effect on toughness values}

The influence of strength mismatch on ${ }_{\mathrm{v}} E$ and $\delta_{\mathrm{cr}}$ was discussed using numerical analysis of the stress field. This study adopted the Weibull stress criterion for determination of the ${ }_{\mathrm{v}} E$ and $\delta_{\mathrm{cr}}$. The Weibull stress ${ }^{7)}, \sigma_{\mathrm{W}}$ was used as a driving force for brittle fracture initiation. The $\sigma_{\mathrm{W}}$ is given by integrating a near-tip stress over the fracture process zone $V_{\mathrm{f}}$ in the form:

$$
\sigma_{W}=\left[\frac{1}{V_{0}} \int_{V_{f}}\left(\sigma_{e f f}\right)^{m} d V_{f}\right]^{1 / m}
$$

where the $V_{0}$ and $m$ are the reference volume and material constant, respectively. $V_{\mathrm{f}}$ almost corresponds to the plastic zone near the crack tip, and $\sigma_{\text {eff }}$ is an effective stress for cleavage fracture that is normally represented by the maximum principle stress. An effective stress $^{8,9)}$ considering a random spatial distribution of microcracks was employed as $\sigma_{\text {eff }}$ in Eq. (2). The selection of $V_{0}$ does not affect the transferability analysis among different specimen geometries, and the shape parameter $m$ value has no relation with $V_{0}$. Hence, a unit volume of $1 \mathrm{~mm}^{3}$ is often used as $V_{0}$ for convenience ${ }^{10)}$. This analysis also adopted $V_{0}=1 \mathrm{~mm}^{3}$. The $V_{\mathrm{f}}$ for the joint specimen was defined in the part consisting of TS400, assuming that the material included crack or $\mathrm{V}$-notch controls the initiation of brittle fracture and the fracture doesn't occur within TS800. It is reported that the brittle fracture initiation of steel structure components can be access by using the Weibull shape parameter, $m=10,20^{11)}$. Accordance with this reference, $m=10$ and 20 were adopted in this study. 


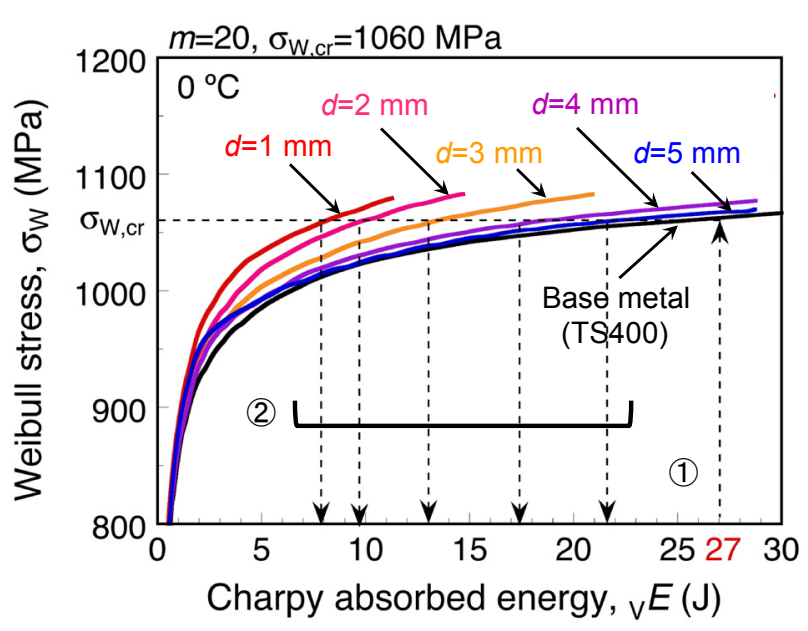

(a) Charpy specimen

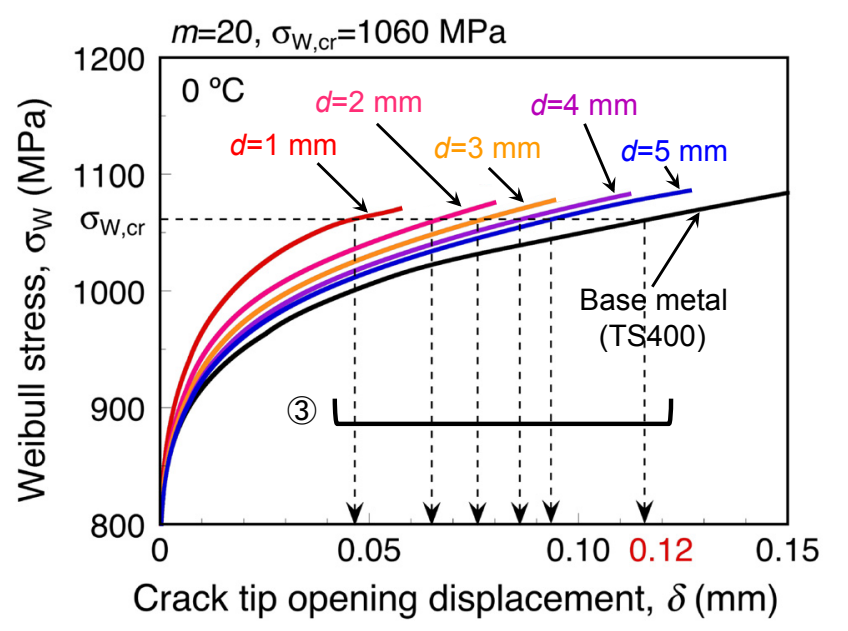

(b) 3PB specimen

Fig. 3 Effect of strength mismatch on Weibull stress

It is reported that the critical Weibull stress is independent of the specimen type, size ${ }^{12)}$, loading rate ${ }^{13)}$ and strength mismatch in $3 \mathrm{~PB}$ specimen ${ }^{4}$. On the basis of these features, ${ }_{\mathrm{v}} E$ and $\delta_{\mathrm{cr}}$ for joint specimen were evaluated by the following procedure:

(1) It is assumed that the CVN-B-specimen is fractured at ${ }_{\mathrm{v}} E=27 \mathrm{~J}$ at $0{ }^{\circ} \mathrm{C}$, which is a required values of steels for welded structure in Japanese Industrial Standard ${ }^{14)}$. The $\sigma_{\mathrm{W}, \mathrm{cr}}$ of TS400 is calculated for each $m$ values $(m=10,20)$ by integrating a near-tip stress over the fracture process zone when the ${ }_{\mathrm{v}} E$ for the CVN-B-specimen is $27 \mathrm{~J}$. In the case of $m=10, \sigma_{\mathrm{W}, \mathrm{cr}}$ was $1130 \mathrm{MPa}$ and, in the case of $m=20$, it was $1060 \mathrm{MPa}$.

(2) The ${ }_{\mathrm{V}} E$ for the CVN-J-specimen is evaluated by means of Weibull stress criterion which is based on the assumption that the $\sigma_{\mathrm{W}, \mathrm{cr}}$ for Charpy specimen is independent of strength mismatch.

(3) Based on the independence of $\sigma_{\mathrm{W}, \mathrm{cr}}$, the $\delta_{\mathrm{cr}}$ for the CTOD-B-specimen and the CTOD-J-specimen are evaluated when their $\sigma_{\mathrm{W}}$ are equal to $\sigma_{\mathrm{W}, \mathrm{cr}}$ for the CVN-B-specimen.

The relationships between the $\sigma_{\mathrm{W}}$ and toughness parameters,

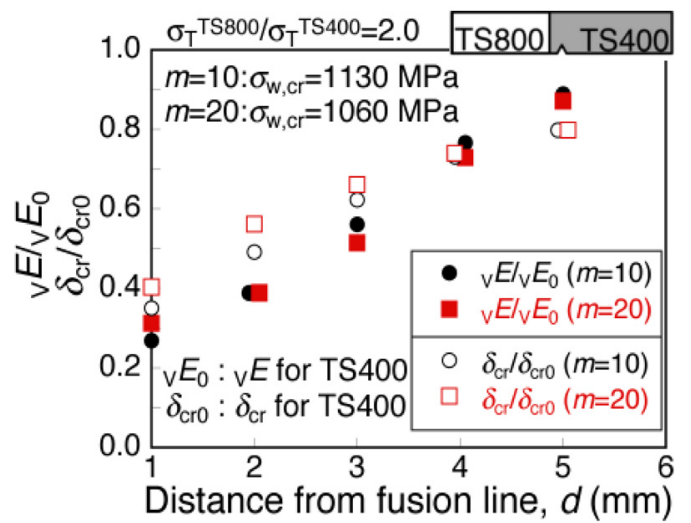

Fig. 4 Effect of strength mismatch on toughness ratios, ${ }_{\mathrm{v}} E / \mathrm{v} E_{0}$ and $\delta_{\mathrm{cr}} / \delta_{0}$ calculated by using $m=20$, are shown in Fig. 3. The $\sigma_{\mathrm{W}}$ for joint specimen was elevated as the FL approached the V-notch or crack.

The effects of strength mismatch on ${ }_{\mathrm{v}} E$ and $\delta_{\mathrm{cr}}$ were investigated on the basis of Weibull stress criterion. The relationships between the toughness ratios and $d$ are shown in Fig. 4. The ratios of ${ }_{\mathrm{v}} E$ and $\delta_{\mathrm{cr}}$ normalized with ${ }_{\mathrm{v}} E_{0}$ and $\delta_{\mathrm{cr} 0}$, respectively, are plotted in Fig. 4 , where the ${ }_{\mathrm{V}} E_{0}$ and $\delta_{\text {cro }}$ mean ${ }_{\mathrm{V}} E$ and $\delta_{\text {cr }}$ for the specimen of base metal, respectively. The ${ }_{\mathrm{V}} E$ and $\delta_{\text {cr }}$ for joint specimen were lower compared with ${ }_{\mathrm{V}} E_{0}$ and $\delta_{\text {cr0 }}$, respectively, although the material at the $\mathrm{V}$-notch root or crack tip was the same material as the specimen of base metal. The ${ }_{\mathrm{v}} E$ and the $\delta_{\text {cr }}$ decreased with the FL close to the V-notch or crack. In the case of $d \leqq 3 \mathrm{~mm}$, the ${ }_{\mathrm{V}} E /{ }_{\mathrm{V}} E_{0}$ was smaller than $\delta_{\mathrm{cr}} / \delta_{\mathrm{cr} 0}$. On the other hand, in the case of $d=5 \mathrm{~mm}$, the ${ }_{\mathrm{V}} E /{ }_{\mathrm{V}} E_{0}$ was larger than $\delta_{\mathrm{cr}} / \delta_{\mathrm{cr} 0}$.

\section{Strength mismatch effect on strain/temperature fields}

The cause of this difference was discussed in terms of the

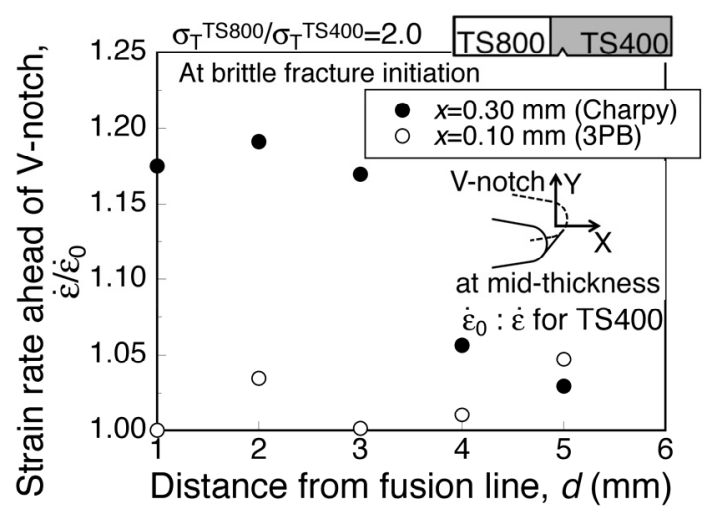

Fig. 5 Effect of strength mismatch on strain rate near the V-notch at brittle fracture initiation 
difference of loading rate between the Charpy impact test and the CTOD fracture toughness test. Under the impact loading condition, high-speed straining increases the flow stress. The strain rate ahead of the V-notch, $\dot{\varepsilon}$, at brittle fracture initiation is shown in Fig. 5. The ratio of $\dot{\varepsilon}$ normalized with $\dot{\varepsilon}_{0}$ is plotted in Fig. 5, where the $\dot{\varepsilon}_{0}$ means the $\dot{\varepsilon}$ for CVN-B- or CTOD-B-specimen at brittle fracture initiation. The $\dot{\varepsilon}$ was examined at high stress field. The distance from notch and crack tip, $x$ was $0.3 \mathrm{~mm}$ (Charpy specimen) and $0.1 \mathrm{~mm}$ (CTOD specimen), respectively. The strain rate was calculated from the increment of the equivalent plastic strain with time. In the case of $d \leqq 3 \mathrm{~mm}$, the $\dot{\varepsilon}$ for CVN-J-specimen was accelerated by strength mismatch. Oppositely, in the case of $d \geqq 4 \mathrm{~mm}$, the

strain rate for CVN-J-specimen was hardly accelerated. Because the harder material is less deformed than softer material, the plastic deformation occurred and developed in the softer material preferentially. Thus, the harder material adjacent to the V-notch provided the acceleration of strain rate for CVN-J-specimen.

Under the impact loading condition, adiabatic deformation raises the temperature of specimen. The temperature rise at brittle fracture initiation, $\Delta T$ is shown in Fig. 6. In the case of the CVN-J-specimen, the $\Delta T$ increased with increasing in $d$ and the $\Delta T$ for CVN-B-specimen was the largest. As shown in Fig. 5, the strain rate was accelerated when FL close to $\mathrm{V}$-notch and the high strain rate decreased the ${ }_{\mathrm{v}} E$. Thus, the plastic deformation in the CVN-J-specimen was smaller than that in the CVN-B-specimen. The temperature rise for CVN-B-specimen increased because the plastic deformation was large. The temperature rise decreases the flow stress. In this study, it was assumed that the critical Weibull stress was independent of temperature. Thus, this increase in temperature rise for CVN-B-specimen expanded the difference of the ${ }_{\mathrm{V}} E$ between CVN-B- and CVN-J-specimen.

In the case of fracture toughness test, the strain rate was affected by the strength mismatch, as shown in Fig. 5. The acceleration was smaller than that for the Charpy specimen. The

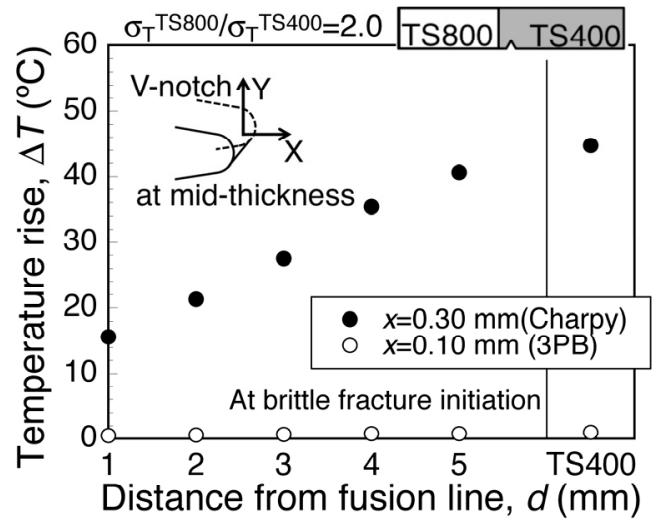

Fig. 6 Effect of strength mismatch on temperature rise near the V-notch at brittle fracture initiation strain rate for CTOD-J-specimen is about $5 \times 10^{-4} / \mathrm{s}$. Therefore, the elevation of flow stress by acceleration of strain rate was small. Figure 6 shows that temperature rise were negligibly small, and the strength mismatch didn't affect the temperature rise. The flow stress near crack-tip was affected only by plastic constraint. On the other hand, in the case of the Charpy impact test the flow stress was affected by acceleration of strain rate and suppression of temperature rise, besides plastic constraint. Above all, because of the difference of the loading rate, the sensitivities of the ${ }_{\mathrm{V}} E$ and $\delta_{\text {cr }}$ on strength mismatch were different from each other.

In the case of $d$ was $5 \mathrm{~mm}$, the $\delta_{\mathrm{cr}} / \delta_{\mathrm{cr} 0}$ was smaller than ${ }_{\mathrm{V}} E /{ }_{\mathrm{V}} E_{0}$. As shown in the Fig. 3, the Weibull stress for CVN-J-specimen was hardly elevated. On the other hand, that for CTOD-J-specimen was elevated compared with CTOD-B-specimen. In the case of the CVN-J-specimen, the plastic constraint, the effects of strength mismatch on strain rate and the temperature rise were small. On the other hand, in the case of CTOD-J-specimen, the plastic constraint was occurred when $d$ was large.

\section{Conclusion}

In this study, the difference between the sensitivity of Charpy absorbed energy and critical CTOD to strength mismatch was investigated, on the basis of the Weibull stress criterion for brittle fracture. It was found that the Charpy absorbed energy was more affected by strength mismatch than critical CTOD when the fusion line was close to the V-notch and crack. The cause of this effect of strength mismatch on toughness values was discussed in terms of the difference of the loading rate between the Charpy impact test and CTOD fracture toughness test. In the case of the Charpy specimen subjected to impact loading, the strain rate for CVN-J-specimen, especially $d \leqq 3 \mathrm{~mm}$, was accelerated by strength mismatch. Because of this, the stress field for the CVN-J-specimen was elevated, and the ${ }_{\mathrm{v}} E$ for CVN-J-specimen was smaller than that for CVN-B-specimen. Then, the temperature rise for CVN-J-specimen decreased with the FL close to the V-notch. In this study, it was assumed that the $\sigma_{\mathrm{W}, \mathrm{cr}}$ was independent of the strain rate and temperature. On the other hand, the flow stress depends on them. Accordingly, because of the acceleration of strain rate, especially $d \leqq 3 \mathrm{~mm}$, and the suppression of temperature rise for the CVN-J-specimen by strength mismatch, the ${ }_{\mathrm{V}} E$ for $\mathrm{CVN}-\mathrm{J}$-specimen was smaller than CVN-B-specimen. On the other hand, in the case of the CTOD fracture toughness specimen subjected to static loading, the effects of strength mismatch on strain rate and temperature rise 
are negligibly small. Thus, because of the difference of the loading rate, the sensitivities of Charpy absorbed energy and critical CTOD to strength mismatch were different from each other. This result implies that when considering the correlation between the Charpy absorbed energy and fracture toughness value in welds, the difference between the sensitivity of the Charpy absorbed energy and fracture toughness value to strength mismatch should be taken into account.

\section{Reference}

1) J.M. Barsom: Development of the AASHTO Fracture-Toughness Requirements for Bridge Steels. Engineering Fracture Mechanics, 7, (1975), 605-618.

2) K. Seo, J. Masaki: Physical Interpretation for the Upper Shelf Energy of Wels Zone in Charpy Impact Test. Journal of the Japan Welding Society, 51, (1982), 291-297. (in Japanese)

3) Y. Takashima, Y.S. Yamada, T. Handa, S. Igi, K. Oi, F. Minami: Numerical Analysis of Strength Mismatch Effect on Stress Field in Charpy Specimen. Welding in the World, 59, (2015), 433-441.

4) M. Ohata, F. Minami, M. Toyoda: Evaluation of HAZ Fracture Toughness of Welded Joints with Strength Mis-Matching by the Local Approach. Quarterly Journal of the Society of Naval Architects of Japan, 180, (1996), 565-573. (in Japanese)

5) P.E. Bennett, G.M. Sinclair: Parameter Representation of Low-Temperature Yield Behavior of Body-Centered Cubic Transition Metals. Transaction of the American Society of Material Engineers, 88, (1966), 557-564.

6) G.I. Taylor, H. Quinney: The Latent Energy Remaining in a Metal after Cold Working. Proceedings of Royal Society of London, A143,
(1934), 307-326.

7) F.M. Beremin: A Local Criterion for Cleavage Fracture of a Nuclear Pressure Vessel Steel. Metallurgical and Materials Transactions A, 14A, (1983), 2277-2287.

8) F. Minami, A. Brückner-Foit, B. Trolldenier: Numerical Procedure for Determining Weibull Parameters Based on the Local Approach. Proceedings of the 8th European Conference on Fracture, ECF8 (1990), 76-81.

9) C. Ruggieri, F. Minami, M. Toyoda, Y. Hagiwara, T. Inoue: Loca Approach to Notch Depth Dependence of CTOD Results. Journal of the Society of Naval Architects of Japan, 171, (1992), 493-499.

10) F. Minami, A. Brückner-Foit, D. Munz, D. Trolldenier: Estimation Procedure for the Weibull Parameters Used in the Local Approach. International Journal of Fracture, 54, (1992), 197-210.

11) ISO 27306: Metallic materials - Method of constraint loss correction of CTOD fracture toughenss for fracture assessment of steel components. International Organization for standardization (ISO 27306), First edition(2009)

12) F. Minami, C. Ruggieri, M. Ohata, M. Toyoda: Evaluation of Specimen Geometry Effect on Brittle Fracture Resistance Based on the Local Approach. Journal of the Japan Welding Society, 45, (1996), 544-551. (in Japanese)

13) F. Minami, T. Hashida, M. Toyoda, J. Morikawa, T. Ohmura, K. Arimochi, N. Kanda: Dynamic Fracture Toughness Evaluation of Structural Steels Based on the Local Approach: Application of the Local Approach to Fracture Control Design (Part 3). Quarterly Journal of the Society of Naval Architects of Japan, 184, (1998), 453-464. (in Japanese)

14) JIS 3106: Rolled steels for welded structure. Japanese Industrial Standard (JIS 3106), (2008). 